\title{
50 PEDAGOGICA
}

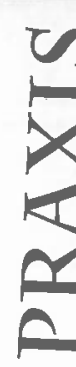

Martha R. Campos

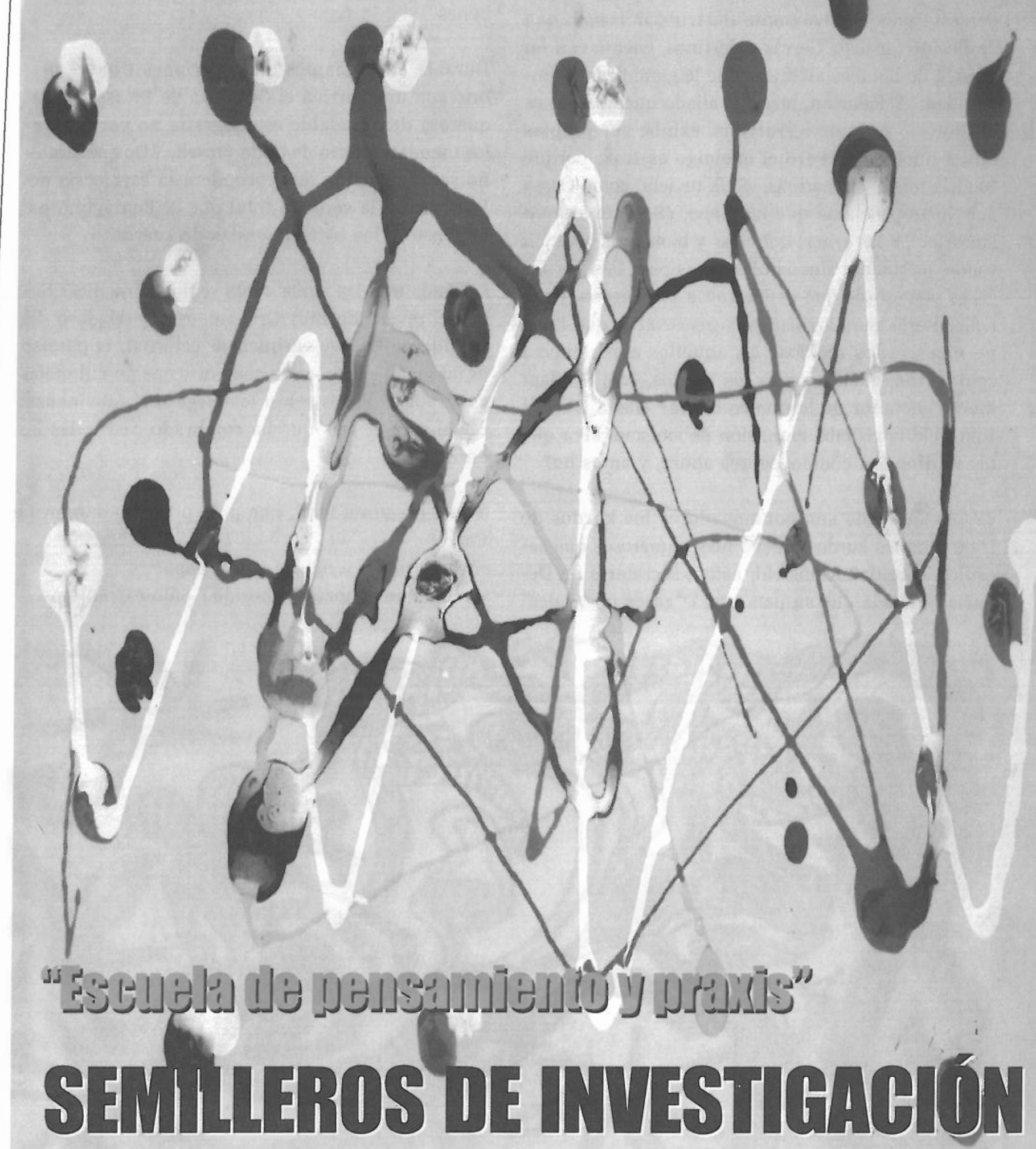




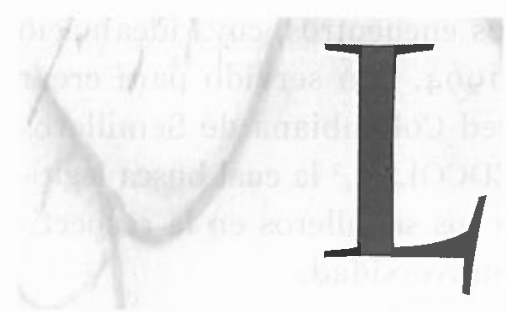

a Universidad Minuto de Dios, como sistema, concibe dentro de su Proyecto Educativo políticas que apoyan la formación integral, entendidas como una forma de educación que pretende el desarrollo armónico de todas las dimensiones de la persona: corporal, espiritual, psicológica, intelectual, de conformación de relaciones. Con todos estos aspectos interconectados, incluidos docentes y estudiantes, se pretende abarcar a toda la persona.

Ella - la Universidad - pretende, entonces, la configuración de una persona que integre el saber con el obrar, competente para transmitir a la sociedad el ideal de vida y de cultura como agente de cambio comprometido. Ahora bien, para hacer posible dicho planteamiento, se requiere del auténtico conocimiento, que no es saber acumulado sino visión de conjunto, anhelo de unidad y totalidad $y$, en cuanto tal, trascender todas las ramas del conocimiento.

A partir de esa visión, la investigación y la proyección social alcanzan una dimensión especial que logra dar sentido al progreso de las personas y de la sociedad; además, buscan motivar para haya corresponsabilidad en la promoción de la justicia y en la defensa de los más débiles.

Se espera, entonces, que mediante esta formación integral los investigadores:

Docente Proyectos de Grado, Facultad de Educación, Uniminuto sus capacidades en la búsqueda de la excelencia académica, por vía del estudio y la investigación y alcancen la capacidad de relacionar sus conocimientos con los de otras disciplinas.

- Desarrollen hábitos reflexivos y críticos que les permita mantener abierta su voluntad de indagar, conocer y aplicar.

- Desplieguen la creatividad que les permita buscar la novedad, los problemas y conflictos así como el valor de las dimensiones estética y lúdica del ser humano.

- Adquieran espíritu de trabajo en equipo y valoren la comprensión interdisciplinaria.

En consecuencia, dentro de las líneas de acción de la Universidad Minuto de Dios aparece como primera la de los procesos académicos a cargo de la Vicerrectoría Académica: atiende lo relacionado con la planeación, gestión, control y evaluación de todos los procesos académicos, pedagógicos e investigativos, con un enfoque principalmente hacia los estudiantes y docentes, con base en las necesidades que se manifiesten por la Universidad y el medio ambiente, en estricto cumplimento del Proyecto Educativo Universitario como sistema educativo. ${ }^{1}$

Por otra parte y como compromiso institucional, uno de los planteamientos dentro de la Visión de la Universidad Minuto de Dios es del propiciar la producción colectiva de conocimientos de alto ni-
- Logren competencia profesional, se comprometan con todas 
vel, con procesos de investigación científica que exijan la articulación entre teoría y práctica, en aspectos humanísticos, sociales, técnicos y tecnológicos.

En ese contexto nació la idea en Vicerrectoría Académica de la creación del semillero de investigación, denominado "Escuela de Pensamiento y Praxis". Este espacio pretende convertirse en apoyo a la formación integral de docentes y de estudiantes comprometidos en la búsqueda de la excelencia académica; propende por el desarrollo de la creatividad entendida como la indagación de la novedad y los problemas educativos y pedagógicos. Su mayor pretensión es la adquisición del espíritu de trabajo en equipo y la valoración en la comprensión interdisciplinaria.

\section{¿QUÉ ES EL SEMILLERO DE INVESTIGACIÓN PARA LA CUMD?}

La noción de semillero de investigación se ha extendido a otras universidades del país en búsqueda de la excelencia académica, como una manifestación investigativa que está tomando cada vez más fuerza en la universidad pública y en la privada, bajo el convencimiento de que se trata de una nueva forma organizativa que va a cambiar la dinámica del aprendizaje en muchos lugares.

Dicha disposición invita a los profesores a socializar experiencias significativas en el ámbito de la investigación $\mathrm{y}$, a los estudiantes, a participar voluntariamente para fortalecer la cultura investigativa y romper con el falso paradigma de subestimar al educando de pregrado que está en capacidad de investigar y de proponer ideas innovadoras. Se considera, por tanto, que esta decisión es una contribución al desarrollo científico, tecnológico y social.

Hasta el momento, se han realizado cinco encuentros a nivel nacional. El primero en Junio de 1998, en la ciudad de Manizales, liderado y organizado por las universidades de Antioquia y de Caldas; allí surgió la idea de la red. El segundo encuentro lo realizó la Universidad de Antioquia en Medellín en octubre de 1999. Un tercero, en Octubre de 2000, en la Universidad del Cauca. El cuarto tuvo como sede la capital santandereana, en la Universidad Autónoma de Bucaramanga, en Octubre de 2001; en esta ocasión se contó con la presencia de la Corporación Universitaria Minuto de Dios. Finalmente, el quinto se realizó en la Ciudad de Tunja, en el 2003, organizado por la Universidad Pedagógica. Con este mismo propósito de semilleros de investigación -se conoció antes de la publicación de este articulo-, el próximo encuentro se realizará del 9 al 12 de Octubre en la Universidad Santiago de Cali; será otra oportunidad para el acercamiento de estudiantes y docentes de todo el país en el terreno de la investigación y el lugar donde se compartan otras experiencias del trabajo en red y donde se haga la evaluación y el redireccionamiento de su operar formativo.
Estos encuentros, cuya idea nació en 1994, han servido para crear la red Colombiana de Semilleros (REDCOLSI), ${ }^{2}$ la cual busca legitimar los semilleros en la respectiva universidad.

Por esta razón, la calidad de las semillas -para nuestro caso, el estudiante o docente de la Universidad Minuto de Dios- está respaldada por los controles de calidad, donde se determina su calidad investigativa en germinación y vigor, y su fidelidad con el compromiso de colocar todas sus capacidades en la búsqueda de la excelencia académica. Nuestras semillas, además, son formadas en el ámbito investigativo con miras a mejorar el hábito reflexivo, crítico e innovador, de tal manera que dicha formación contribuya a mantener abierta su voluntad de indagar y conocer.

La conservación de esta semilla donde se gestan cambios personales que integran el saber con el obrar-, que es competente para transmitir a la sociedad el ideal de vida y de cultura que en sí misma han realizado, es tal que logra dar sentido al progreso de las personas y de la sociedad. Se pretende mantenerlas en su envase original, como respeto a la singularidad, en un lugar de discusiones educativas y pedagógicas, desde donde se logren los conocimientos necesarios para su propia transformación y, así, lograr una competencia profesional que comprometa todas sus capacidades en la búsqueda de la excelencia académica, bajo la premisa de la investigación y donde 
se relacionen sus conocimientos con los de otras disciplinas.

Por lo tanto, estas semillas no tienen caducidad en el tiempo; al contrario, los semilleros permiten la integración en las diferentes áreas del saber, como proyección académica, pues como seres vivientes, la semilla de la investigación que se tiene en el ámbito universitario se debe dar por periodos largos de duración para que ayuden a consolidar la formación integral; se entiende así como una forma de educación que pretende el desarrollo armónico de todas las dimensiones de la persona.

Sin duda, desde una mirada así, el semillero, además de mejorar la calidad académica de sus integrantes, los vincula a proyectos, posibilita que asistan a congresos, que participen y organicen encuentros; también, los enriquece afianzando sus conocimientos en pedagogía, metodología y didáctica específica; fortalece su capacidad para hablar en público; les permite adquirir una cultura crítica frente a diversos temas: en el campo científico y también en temas sociales como los problemas de la Universidad, el papel y la responsabilidad ante la sociedad y los aportes que se pueden hacer a través de la investigación. El semillero estimula la reflexión y la discusión sobre el quehacer: sus integrantes no solamente participan en un proyecto, también, gracias a la oportunidad que se brinda desde el pregrado, ${ }^{3}$ conocen la dinámica de la investigación, interactúan con personas que tienen un amplio recorrido en este campo, proponen nuevas ideas y proyectos. En otras palabras, los miembros del semillero son la vivencia y evidencia de un nuevo modelo de aprendizaje.

El semillero ha producido algo muy importante: aprender por el deseo que se tiene del conocimiento; es un aprendizaje voluntario y a la vez placentero, ya que no se parte de la preocupación por una nota. De esta manera, todos los miembros del semillero preguntan, discuten y participan sin ningún condicionamiento y así, poco a poco, adquieren la visión crítica ante cualquier tema o situación.

En conclusión: "Escuela de Pensamiento y Praxis" apoya la idea

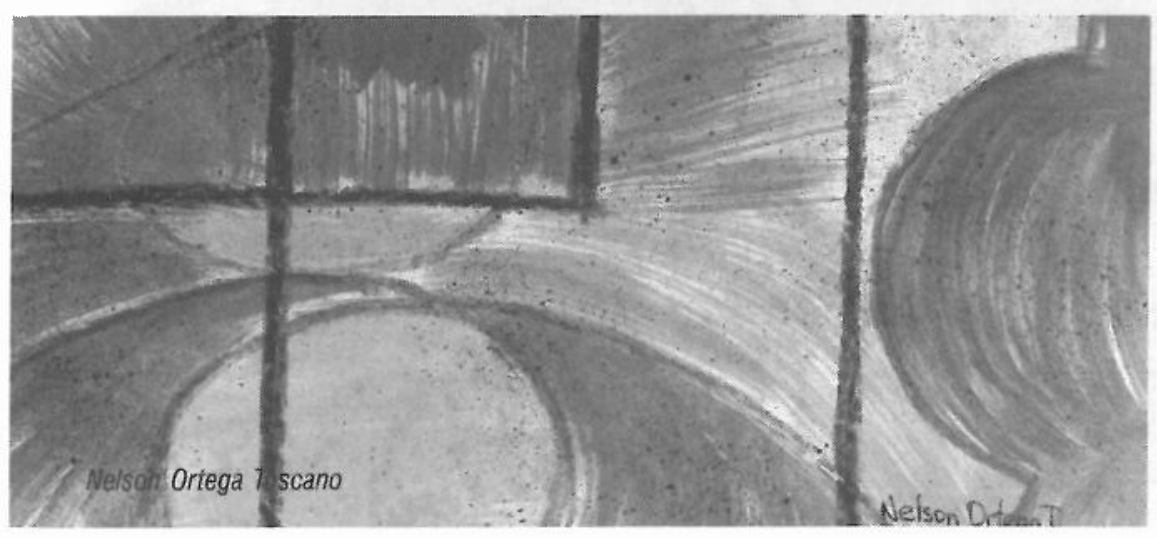

de nuestro Padre Rector, Camilo Bernal Hadad, en coordinación con la Vicerrectoría Académica, ${ }^{4}$ dentro del plan de desarrollo Uniminuto, de la creación del semillero para docentes denominado «Didáscalos». Se pretende, así, consolidar un nodo educativo que teja finamente los hilos sueltos, los esfuerzos aislados, en unidad abierta y con la voluntad de indagar y conocer, en coherencia con el campo de investigación institucional. ${ }^{6}$

Finalmente, hacia el exterior, el semillero se consolidará ante otras instituciones como un sistema educativo alternativo, participativo y anticipatorio, de puertas abiertas a la investigación interdisciplinaria que, al unísono, cimentará y proyectará la Colombia que soñamos. 5

\section{Pie de Notas}

1 Modelo Educativo Uniminuto, Versión 2,2, 2002.

2 REDCOLSI. Como Red fomentay apoya la formación de Semilleros de Investigación a nive/ nacional, propiciando un espacio para la investigación a través del intercambio de experiencias de los grupos que la promueven y realizan. Para ello, y como parte de su plan estratégico, trabaja por nodos. Éstos agrupan, por ciudades o regiones, las distintas instituciones académicas del país. No sólo están representadas las instituciones de educación superior, sino también toda aquella entidad que conforme y apoye los Semilleros de Investigación.

3 Estas oportunidades se han ampliado durante los uiltimos tres semestres por parte de los docentes al interior de la Facultad. Hay una mayor participación de estudiantes en los diferentes grupos -diseño de ambientes, tecnologia y praxeologia- con la perspectiva de que dichos proyectos posibiliten el pensar los problemas actuales de la educación y la pedagogía.

4 Corporación Universitaria Minuto de Dios, Consejo Académico, Acta 110 (8, may, 2003).

5 Modelo Educativo Uniminuto; versión 2.2 de 2002, p. 14. 